DOI 10.37882/2223-2982.2020.12-3.21

\title{
КУЛЬТУРА ОБРАЗОВАНИЯ И ОСОБЕННОСТИ ЕЕ ТРАНСФОРМАЦИИ В ОПТИКЕ СОЦИАЛЬНО-ГУМАНИТАРНОГО ЗНАНИЯ 1
}

\section{CULTURE OF EDUCATION AND FEATURES OF ITS TRANSFORMATION IN THE OPTICS OF SOCIAL AND HUMANITARIAN KNOWLEDGE}

\section{E. Susimenko} A. Efimov

Summary: This article raises, updates and discusses in a discursive way the issues that make up the problem field of the functioning of education in a modern society that has entered the digital age. In the Russian reality, these issues receive mostly critical coverage, however, the palette of opinions is quite diverse, and the author's analysis allows us to fix the contradictory background of attitudes to changes both in the Russian education system and in the culture of education.

Analysis of positions and opinions regarding culture of learning allowed the author to state that this concept in the field of socio-humanitarian knowledge presented fairly fragmented, mostly in the context of largescale changes in the education system, problems and contradictions of the transition to digital education, to his onlinesale and information. The methodological field of the culture of education has also not been the subject of separate scientific research, which in a promising light presents the problems chosen by the author in the context of topical questions about the current and future state of the culture of education in Russia and the risks of its imitation. The author comes to this conclusion by the very nature and assessment of the digital reform of the Russian education system. If most of the country's educational space is not ready to switch to digital education, both at the psychological and technological level, the processes of imitation of education are inevitable.

Keywords: culture, education, culture of education, digitalization, Informatization, digitalization of education, onlinization, globalization.
Сусименко Елена Владимировна

д.ф.н., профессор, Южно-Российский государственный политехнический университет (НПИ)

имени М.И. Платова, г. Новочеркасск

lesusima@yandex.ru

Ефимов Александр Владимирович

к.э.н., доцент, Южно-Российский государственный политехнический университет (НПИ) имени М.И. Платова, г. Новочеркасск npi_pfu@mail.ru

Аннотация: В данной статье поднимаются, актуализируются и рассматриваются в дискурсивном ключе вопросы, составляющие проблемное поле функционирования образования в условиях современного общества, вступившего в цифровую эпоху. В российских реалиях эти вопросы получают в своем большинстве критическое освещение, однако, палитра мнений достаточно разнообразна, и проведенный автором анализ позволяет зафиксировать противоречивый фон отношения к изменениям как в российской системе образования, так и в культуре образования.

Анализ позиций и мнений относительно культуры образования позволил автору констатировать, что данное понятие в области социально-гуманитарного знания представлено достаточно фрагментарно, в основном, в контексте масштабных перемен в самой системе образования, проблем и противоречий перехода к цифровому образованию, к его онлайнизации и информатизации.

Методологическое поле культуры образования также не стало предметом отдельных научных исследований, что в перспективном свете презентует выбранную автором проблематику в контексте актуально сформулированных вопросов о современном и будущем состоянии культуры образования в России и рисках ее имитации. К этому выводу автора подводит сам характер и оценка цифрового реформирования российской системы образования. В условиях неготовности к переходу на цифровое образование большей части образовательного пространства страны как на психологическом, так и технологическом уровне, запущенные процессы имитации образования неминуемы.

Ключевые слова: культура, образование, культура образования, цифровизация, информатизация, цифровизация образования, онлайнизация, глобализация.

ческого капитала [7], а потому оно должно находиться в фокусе общественного и научного внимания. Сами же образовательные процессы должны быть подконтроль-

Статья выполнена в рамках реализации гранта Президента Российской Федерации для государственной поддержки ведущих научных школ Российской Федерации (НШ-2582.2020.6) на тему «Государственная политика в сфере высшего образования и развитие инновационного потенциала молодежи: экономические и неэкономические детерминанты и механизмы в условиях регионализации социального пространства и становления индустрии 4.0». 
ны социальной регуляции. Только так можно управлять системой образования и прогнозировать тенденции образовательной динамики и изменение парадигмальных оснований образования как социального института. Вместе с тем, как отмечают исследователи, «процессы, происходящие в образовании, вырываются из-под контроля как институтов, так и субъектов образовательного процесса. Это можно наблюдать как в практиках образования на всех уровнях, так и в теории, которая зачастую не в состоянии совместить новые направления исследований с традиционными представлениями о смысле и ценности образования» [19].

Иными словами, образование развивается по стихийной траектории, задаваемой рынком, который, в свою очередь, ориентируется на прагматические ценности, уже явно доминирующие над инструментальными и сформировавшие потребительские модели поведения. Последние стали постепенно вытеснять созидательные, культуротворящие, и эти реалии сегодняшнего дня определяют негативные стратегии развития не только образовательной сферы российского общества, но и всей социальной сферы, находящейся в непосредственной зависимости от эффективности института образования, его способности задавать ориентиры будущего в соответствии с духом современности.

Негативные реалии в сфере российского образования требуют поиска ответа на вопрос об источниках их появления и распространения. Безусловно, источники кризисных факторов в социокультурной динамике российского общества и его системы образования в определенной мере детерминированы мировыми тенденциями и факторами, связанными с цифровизацией, информатизацией социальной сферы [2] и образования в том числе [5], но и внутренние факторы не стоит сбрасывать со счетов. Очевидно, следует учитывать влияние процессов, производных от факторов внутренней среды, оказывающих воздействие на ценностную трансформацию института образования, на академическую среду с ее этосом, корпоративной культурой и культуру образования в целом.

Можно говорить о том, что в системе образования совершился парадигмальный переход, кардинально изменивший саму культуру образования как фундаментальное основание образовательного пространства российского общества. Этот переход обусловлен внедрением в образовательную сферу, в образовательные практики компьютерных информационно-коммуникативных технологий, в результате чего актуально зазвучали проблемы сетевизации, виртуализации, онлайнизации и кибернетизации образовательной среды и образования в целом [3].

Относятся к данным процессам ученые по-разному, выделяя как преимущества информатизации образовательной сферы и среды, так и ее негативные стороны, но всеми признается необходимость соответствовать мировым трендам цифровизации в силу тотального проникновения информационных и цифровых технологий в социальную жизнь, и образование как базовый социальный институт не моет остаться в стороне [8].

Другое дело, что переход к цифровому образованию не должен сопровождаться сокрушительным ударом по социокультурному базису образования, формировавшемуся в логике цивилизационной динамики общества, его мировоззренческих оснований и культурных традиций, но именно так происходит в российской образовательной сфере. И не только образовательной. Масштабный переход на информационные способы и средства управления в социальной сфере, в области управления, экономики и политики сформировал пространство информационных рисков [13], в системе образования выразившихся в тенденциях стандартизации, унификации, упрощения образовательного процесса, утраты глубинных смыслов образования, роста имитационных схем и стратегий в образовательных практиках, в управлении ими [12].

Сложно понять, на что рассчитано разрушение социокультурного базиса образования с его колоссальным дидактическим опытом, потенциалом научных школ, когда совершенно очевидно, что только взращенные на традициях инновации, имеющие под собой социокультурные основания, могут, действительно, стать фактором инновационного прорыва общества [15]. Иные же отторгаются самим обществом или порождают архаические процессы с параллельным наращиванием практик, имитирующих инновационные. И в сфере образования, по свидетельству российских философов, все указанные процессы имеют место быть, что не противоречит самой архаической траектории развития современного российского государства [10].

Что же происходит с культурой образования в современной России? Какие проблемы поднимаются в научном дискурсе в свете очевидных культурных изменений функционирования российской системы образования? Какими смыслами, ценностями, идеалами наполнено современное пространство культуры образования в России и есть ли она как целостное социальное явление?

На данные вопросы еще нет исчерпывающих ответов, но они уже сейчас находятся в оптике научной рефлексии, и в ее рамках можно выделить ряд направлений, которые привлекают особое внимание исследователей.

Прежде всего, ученые обращаются в современной информационной реальности, к цифровой революции, обосновывая этими процессам ту или иную точку зре- 
ния на культурные формы и ценности образования в изменившихся условиях. Так, Н.Л. Варова, определяющая культуру образования по признакам направленности на развитие личности и качество знания, видит ее миссию в сохранении и развитии современной цивилизации, что предполагает наличие у человека восприятия мира как целого и личности как самоценности; отношение к различиям как источнику новых знаний о мире, его развития, и с этими задачами в системе высшего образования, по мнению данного автора, способна справиться философия [4].

Ю.В. Агапов ратует за «необходимость обновления самой культуры образования как условия становления полноценного субъекта учебной деятельности путем приобретения успешного опыта самостоятельной рефлексивно организованной учебной и познавательной активности» [1]. В свою очередь, В.С. Глаголев, отталкиваясь от информационных реалий современного мира, определяет в качестве приоритетных направлений повышения культуры образования современного российского общества те, которые связаны, во-первых, с совершенствование информационной культуры субъектов образовательного процесса для более эффективной работы с информационными потоками в рамках развития научного мышления и навыков аналитической работы; во-вторых, с обращением к подлинному, лишенному идеологических спекуляций, культурному наследию общества; в-третьих, с повышением правовой грамотности всех участников образовательных отношений; в-четвертых, с повышением уровня профессионализма и научной компетентности; в-пятых, сохранение и поддержание на высоком уровне гуманитарного блока образовательной программы и образовательной системы в целом [6].

Есть среди исследователей те, которые полностью принимают современные информационные веяния, полагая, что система высшего образования должна адаптироваться к ним беспрекословно $[11 ; 16]$, так как в противном случае сам преподаватель высшей школы становится источником рисков в процессе информатизации образования в силу психологической неготовности к использованию цифровых технологий в образовательной деятельности; убежденности в том, качество образования и использование цифровых и электронных ресурсов никак не связаны между собой; невысоким уровнем информационно-коммуникационной компетентности; сопротивления новым дидактическим практикам и отстаивания устоявшейся практики преподавания; негативной мифологизации процессов информатизации в сфере образования и других областях жизнедеятельности современного социума [20; с. 24].

Не разделяя такой безальтернативности к организации образовательного процесса и дидактической практики преподавателей, даже учетом масштабного процесса информатизации социальной сферы, мы, скорее, солидарны с теми учеными, которые убедительны в своем объяснении института образования и образовательных отношений как развивающихся по собственной логике, отличной от логики развития экономических систем и институтов [9], имеющих свое функциональное предназначение, свою миссию в социокультурной динамике общества. Не отрицая преимуществ цифровизации образования и внедрения электронных технологий и средств в образовательный процесс, следует, как справедливо полагают ученые, учитывать и производные от цифровизации риски: уход от фундаментальности, снижение статуса российского образования, «утечка» талантливой молодежи за границу, дефицит личных контактов в образовательном процессе и т.д. [14].

Образование всегда отвечало за такой экзистенциальный процесс, как формирование личности, общих смыслов и ценностей как основы целостного восприятия мира и своего места в нем. Да, современное образование попало в информационную ловушку, потому что не справляется с высокой динамикой изменений, информационных потоков, тенденциями стремительного устаревания опыта, технологий и знаний, что затрудняет или сводит к минимуму его способность сохранять преемственность между прошлым и будущим, между поколениями с их экзистенциальным опытом и смыслами жизни. Но это кажущаяся неспособность, кажущееся бессилие, которое проявляет себя в сфере информационных технологий и инноваций, но остается гуманитарная сфера, которая, как и прежде, призвана быть «мостиком» между поколениями, различными культурами, эпохами.

Однако сокращение гуманитарного образования в современной российской системе образования позволяет прогнозировать то, что уже сейчас представляют как данность - крах образования как рупора эпохи, канала социокультурной преемственности. Исправить ситуацию еще возможно. Для этого нужны серьезные и адекватные задаче гуманизации и гуманитаризации образования реформы, программы развития, в рамках которых будет формироваться и развиваться в духе эпохи и целей социокультурного развития общества культура образования. В свою очередь, возникает задача масштабного научного плана, связанная с концептуализацией самой темы культуры образования, представленной в российской науке, в том числе социально-философской, весьма фрагментарно.

Культура образования есть субстанция всей образовательной системы общества. В современных российских реалиях она находится в турбулентном состоянии, как и само общество, переживающее длительный период реформ и экономических кризисов, ценностной 
трансформации. На этом фоне цифровая революция, ворвавшаяся в современный глобальный мир, стремительно закрепляет ценности цифрового мира с приматом не только всего информационного, но и потребительского, что самым разрушительным образом сказывается на культуре образования. Она, будучи частью культуры общества как «поведенческой программы обеспечения коллективного характера жизнедеятельности людей» [18], также утрачивает свои социокультурные основания, рискуя стать придатком рыночной культуры, в российских условиях далекой от цивилизованной, не попирающей силу и значимость человеческих прав и интересов.

В заключении поставим ряд вопросов, которые еще ждут ответа в условиях стремительной цифровой революции и ее победного шествия по миру. Какой должна быть культура образования в цифровую эпоху? Возможна ли она в принципе с учетом высокой динамики изменений цифровой эпохи, мобильного мира, в котором уже не актуальны принципы константности, устойчивости, традиционности, а символом современности выступают такие характеристики, как изменчивость, подвижность, движение, динамика и мобильность как маркер социального успеха [17]?
Очевидно, что современная система образования в России не готова к формированию такого типа личности, такого типа общества, но настойчиво движется в этом направлении, последовательно разрушая все то, что было ориентировано на иной тип общества. Такие крайности в социальной сфере общества, в социальной политике и истории России всегда заканчивались трагично - общество утрачивало целостность, вступало в эпоху социокультурного раскола.

Опасность сегодняшней ситуации, сложившейся в сфере образования, заключается в угрозе имитации образования, поскольку стремительный переход к онлайн-формам образовательных практик и управления в системе образования в условиях психологической и технической неготовности к подобному переходу, если рассматривать ситуацию в целом по стране, а не ее отдельным, наиболее продвинутым в ресурсном и технологическом плане регионам, вузам, автоматически запустил имитационные и симулятивные механизмы. Под угрозой и сама культура образования. Ее имитационные оттенки уже просматриваются в неоднозначной ценностной и смысловой палитре российского образования.

\section{ЛИТЕРАТУРА}

1. Агапов Ю.В. Культура образования и формирование субъекта образовательной деятельности // Грамота, 2013. № 6 (32). Часть 2 [Электронный ресурс]. Режим доступа: www.gramota.net

2. Бакаева Ж.Ю., Степанов А.Г., Степанова С.Е. Философско-методологические основания информатизации и моделирования в контексте цифровизации социума // Контекст и рефлексия: философия о мире и человеке. 2018. Том 7. № 5А. С. 20-27.

3. Богословский В.И., Аниськин В.Н. Роль и место холистичной информационно-образовательной среды на этапе цифровизации процессов обучения и воспитания личности // Самарский научный вестник. 2018. Т. 7. № 4(25). С. 305-311.

4. Варова Н.Л. Культура образования в современной цивилизации // Современные проблемы науки и образования. 2012. № 4 [Электронный ресурс]. Режим доступа: http://science-education.ru/ru/article/view?id=6779

5. Вербицкий А.А. Цифровое обучение: проблемы, риски и перспективы // Электронный научно-публицистический журнал "Homo Cyberus". 2019. № 1(6). [Электронный ресурс] Режим доступа: http://journal.homocyberus.ru/Verbitskiy_AA_1_2019.

6. Глаголев В.С. Культура образования в условиях современного российского общества [Электронный ресурс]. Режим доступа: https://mgimo.ru/upload/ iblock/5e3/kultura-obrazovaniya-v-usloviyah-sovremennogo-rossijskogo-obshchestva.pdf

7. Голенкова 3.Т., Кошарная Г.Б., Кошарный В.П. Влияние образования на повышение конкурентоспособности работников на рынке труда // Интеграция образования. 2018. Т. 22. № 2. С. 262-273.

8. Гребенникова В.М., Новикова Т.В. К вопросу о цифровизации образования. Историческая и социально-образовательная мысль. 2019. Том. 11. № 5. С. 158-165.

9. Культура образования [Электронный ресурс]. Режим доступа: https://potencial-school.ru/kultura-obrazovaniya.html @ potencial-school.ru.

10. Кумыков А.М., Ситников А.П. Архаизация в практиках образования в современном российском обществе // Гуманитарий Юга России. 2019. № 1. С. 261-269.

11. Лапчик М.П., Федорова Г.А. Инновационный подход к подготовке педагогических кадров в области информатизации образования // Преподаватель XXI век. 2016. № 4. С. 28-41.

12. Павленко И.И. Информатизация социального управления и перспективы формирования инновационного университета в России: автореферат дис. ... канд. соц. наук. Ростов-на-Дону, 2015. 41 с.

13. Перчук Е.Е. Информатизация и информационная безопасность: философско-методологические аспекты: диссертация ... кандидата философских наук: 09.00.08. Москва, 2002. 159 c.

14. Стрекалова Н.Б. Риски внедрения цифровых технологий в образовании // Вестник Самарского университета. История, педагогика, филология. 2019. Том 25. № 2. C. $84-88$. 
15. Суркова И.В. Социальная сфера российского общества: на пересечении традиций и инноваций. Ростов-на-Дону: Фонд науки и образования, 2018.142 с.

16. Тюкавкин Н.М. Цифровизация образовательных процессов в вузах // Эксперт: теория и практика. 2019. № 1(1). С. 35-41.

17. Урри Дж. Мобильности / пер. с англ. А. В. Лазарева. М.: Праксис, 2012. 576 с.

18. Флиер А.Я. Теория культуры: опыт генерализации // Культура культуры. 2017. № 4 [Электронный ресурс]. Режим доступа: http://cult-cult.ru/the-theoryof-culture-a-new-generalization/

19. Шапинская Е.Н. Образование в эпоху «цифры»: учение или развлечение? [Электронный ресурс]. Режим доступа: Культура культуры. 2019. № 2 / httр:// cult-cult.ru/education-in-the-digital-age-learning-or-entertainment/

20. Шафранова 0.Е. Дополнительное образование преподавателей как условие минимизации рисков информатизации высшего образования // Научное обеспечение системы повышения квалификации кадров. 2018. № 2. С. 16-24.

( С Сусименко Елена Владимировна (lesusima@yandex.ru), Ефимов Александр Владимирович (npi_pfu@mail.ru).

Журнал «Современная наука: актуальные проблемы теории и практики»

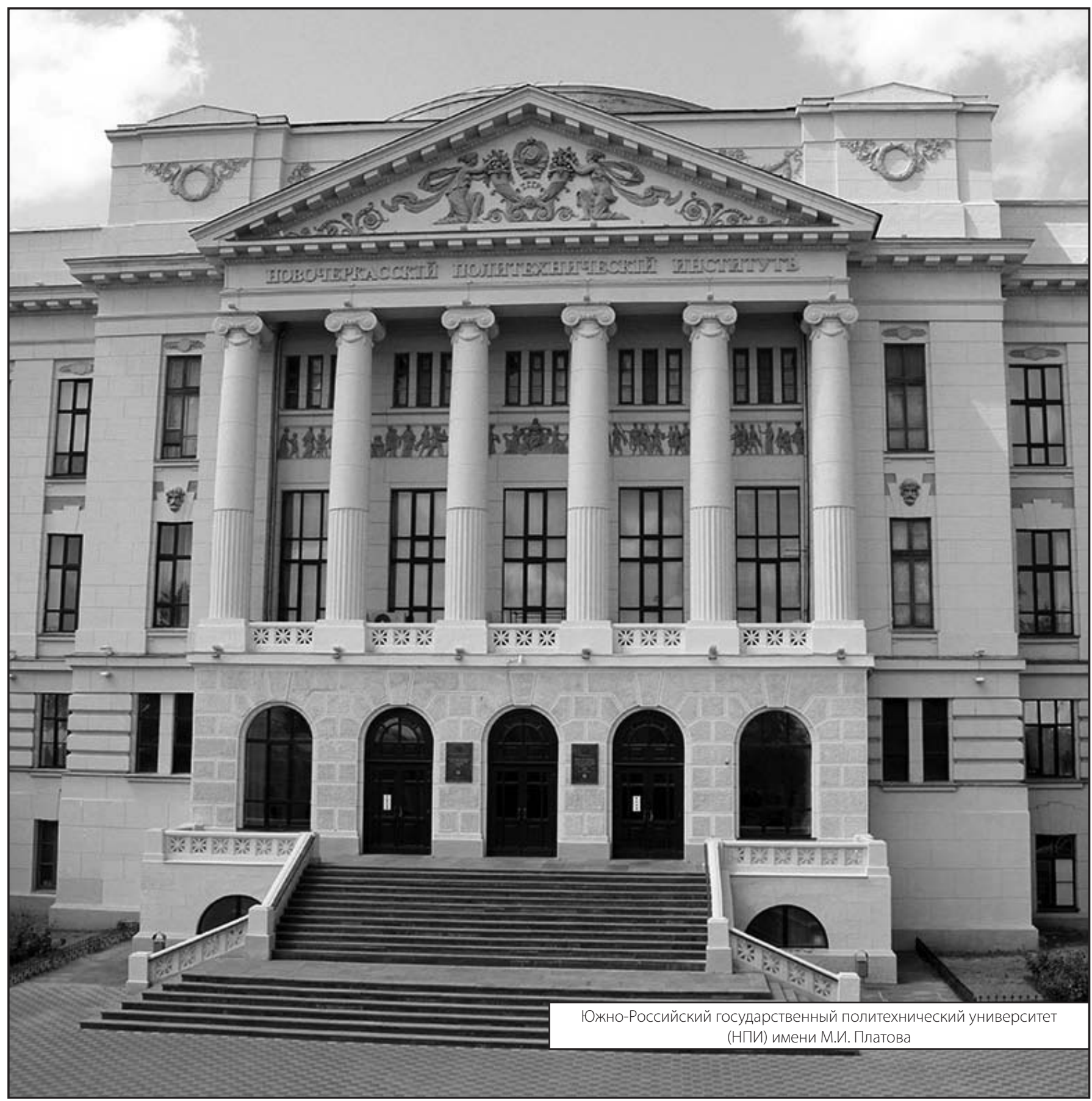

